\title{
PALAZZO LA SAPIENZA IN PISA: STRUCTURAL ASSESSMENT AND RETROFIT OF AN HISTORICAL MASONRY BUILDING IN ITALY
}

\author{
S. Caprili ${ }^{1}$, F. Mangini ${ }^{1}$, N. Mussini ${ }^{1}$ and W. Salvatore ${ }^{2}$ \\ ${ }^{1}$ Department of Civil and Industrial Engineering, University of Pisa \\ Largo L. Lazzarino 1, 56122 Pisa \\ silvia.caprili@ing.unipi.it, f.mangini@ing.unipi.it, nicola.mussini@ing.unipi.it, walter@ing.unipi.it
}

Keywords: Instructions, ECCOMAS Congress, Computational Methods, Engineering Sciences, Proceedings.

\begin{abstract}
Palazzo La Sapienza, historical seat of the University of Pisa since the XVI century, represents one of the most important examples of the Tuscany cultural heritage, nowadays not in use due to several problems related to maintenance and structural deficiencies. The building, in its current form, is the result of several modifications, enlargements, elevations, connection with adjacent parts, resulting finally more similar to a "structural aggregate" made up of single units connected together without specific scheme and organization - than to a single unitary building. After the earthquake of May 2012, the Palace was temporarily closed in relation to the ordinance issued by the Major's Office and then subjected to wide in situ investigations aiming at analyzing in a very detailed manner all the criticisms related to structural, nonstructural, geotechnical and maintenance problems; the deep in situ survey campaigns allowed to reach a very deep knowledge of the building, of its progressive morphological evolution and of its actual condition, including problems not directly related to the structural condition but, as an example, to the instability and heterogeneity of the ground soil and of the foundation system. All the information so obtained allowed the execution of static and seismic vulnerability assessment - according to the actual prescriptions of Italian Standard for Constructions (D.M. 14/01/2008) - through the elaboration of complex global and local models and the final elaboration of an executive retrofit design comprehensive of local interventions on significant structural elements or subportions of the building. In the present paper, after a short description of the knowledge analysis of the building and of its safety verification, the retrofit executed to obtain a satisfying level of safety is presented.
\end{abstract}




\section{INTRODUCTION}

Recent seismic events (i.e., Umbria - Marche 1997, Aquila 2009, Emilia-Romagna 2012) evidenced the high vulnerability of existing masonry cultural heritage and the need to define operational strategies for modifying, improving or locally retrofitting structures (or portions thereof) without altering their original characteristics and ensuring a sufficient margin of structural safety. Such buildings, during the centuries, underwent changes, expansions and reconstructions transforming them from 'single buildings' into 'structural aggregates', often in a significant state of decay caused by insufficient maintenance, earthquakes, collapses, cracking scenarios and so on, consequently evidencing the need to perform extensive static and seismic safety checks to plan suitable retrofit operations.

Several methodologies exist for the execution of seismic vulnerability analysis of monumental buildings. Some of such methods [1,2] classify the buildings basing on a widescale damage analysis together with macroseismic intensity maps, defining vulnerability curves and identifying those structures for which retrofit shall be immediately organized.

Current standards for constructions $[3,4,5]$ foresees the determination of the "Knowledge Level" (KL) - achieved through historical analysis, structural and geometrical surveys, geological and geotechnical investigations and mechanical characterization of materials intended as the degree of uncertainty to be adopted when the safety checks and retrofit are performed.

Several applications aiming at evaluating the seismic behaviour of monumental buildings can be found in the current scientific literature, adopting detailed three-dimensional finiteelement models elaborated basing on the results of laser-scanner surveys and in-situ deep investigations [6,7] analyzing the local behaviour of significant portions of the buildings accounting for the damage scenario revealed [8] or proposing a displacement-based approach considering the ability of historical buildings to sustain earthquakes as long as they have sufficient capacity to move without collapse, so determining different limit states $[9,10,11]$. The problems regarding the numerically modelling of complex structures were widely discussed by [12], finally suggesting the execution of experimental dynamic analyses and investigations of both the whole aggregate and of portions thereof to characterize the structural behaviour of existing buildings.

D.M. 14.01.2008 [3] and the Guidelines of the Ministry for Cultural Heritage [13] prescribe global checks and evaluations of the local collapse mechanisms of significant structural units, identified through the mapping of the critical points from the surveys and the results of the global checks. The assessment of the structural safety of the building shall be executed with reference to different levels of analysis, ranging from large-scale evaluations to the local macro-element models representing independent portions of the whole building. The assessment of existing complex structural aggregates cannot then follow the usual approaches included in modern standards: complex models and cumbersome numerical analyses are not always able to represent masonry structural aggregates; many of the structural and maintenance diseases can be fully understood only through detailed surveys and the correlation between the morphological evolution of the building, its modifications throughout the centuries and its current condition.

A proper methodology, accounting for its intrinsic structural, architectural, geotechnical and functional complexities and their mutual interrelationships, shall be adopted for the safety assessment of a structural aggregate. A deep, extensive and multi-disciplinary approach, combining critical historical studies of the building's evolution, morphological/structural surveys, geotechnical investigations, mechanical characterization of materials and structural/geotechnical monitoring is necessary. 
The present study deals with the assessment of structural safety and seismic vulnerability of the "Palazzo La Sapienza", in Pisa, Italy. The building, site of the University since the $14^{\text {th }}$ century, is currently not in use due to the pending ordinance by the Mayor's Office of May 2012 because of ensuing surveys conducted by Pisa Fire Department. The Palace is a "structural aggregate" made up of interconnected units joined together during more than eight centuries $[14,15,16]$. The building's peculiarity and its importance to the urban setting was a unique occasion for the development and adoption of the multidisciplinary approach above mentioned. Accurate critical historical studies, including reconstruction of the building's evolution over time and detailed architectural surveys through both direct and indirect techniques, allowed identifying the structural units making up the aggregate. Each unit was subjected to accurate studies aiming at determining its structural system, the constituent materials and any critical detail revealed by geometrical and historical investigations, with the following organization of suitable monitoring systems able to identify causes of local (substructures, structural elements and units) and global (structural aggregate) problems. The proper combination of local and global numerical models, used and applied critically because of building complexity, allowed an accurate interpretation of the structural problems recognized by aforementioned multidisciplinary analysis, becoming the real "core" of the assessment procedure (rather than cumbersome, complex and often not representative global, linear and nonlinear, numerical analyses) and of the retrofit interventions, planned to preserve the original nature of the Palace giving a sufficient margin of safety.

\section{STRUCTURAL ASSESSMENT}

\subsection{General presentation of the building}

The building presents a trapezoidal plan (about $80.0 \mathrm{~m} \times 53.7 \mathrm{~m}$ ) with three floors above the ground and a gable roof accessible only for maintenance. The central courtyard, surrounded by a ground-level colonnade and a first-floor arcade running roughly parallel to the ground floor sides, has maximum dimensions of $35.5 \mathrm{~m}$ by $21.2 \mathrm{~m}$. Due to the presence of different types vaulted surfaces and storey slabs, the height of the ground floor varies between $4.30 \mathrm{~m}$ and $5.50 \mathrm{~m}$; similar situations can be found at the first and second floors, with maximum heights respectively equal to $5.60 \mathrm{~m}$ and $5.20 \mathrm{~m}$.

The ground floor of the building houses staff rooms, university classrooms, university department offices and the historical Aula Magna. The $1^{\text {st }}$ floor, besides department offices and the double volume of the Aula Magna Nuova, houses the University Library, covering about two sides of the building (along Piazza Dante square and Vicolo dell'Ulivo at $1^{\text {st }}$ floor and Via della Sapienza and Vicolo dell'Ulivo at the $2^{\text {nd }}$ floor), with mezzanines and loft structures to hold the books. Figure 1 shows the plan of all floors with indication of the use destinations foreseen just before the closure of the Palace.

\subsection{Analysis of the state of art of the Palace}

The analysis of the morphological evolution of the Palace [17] enabled to identify a series of critical structural issues, due to the modifications, heightening, enlargements and loading changes made over the centuries, currently evidenced by the widespread cracking scenario visible in various portions of the building, to be analyzed based on in-depth knowledge of the structure. The structural complexity of the building was confirmed through the extensive campaign of in situ studies, designed on the base of the results of the historical/evolutionary analysis and aiming to reconstruct the current structural condition of the building. 


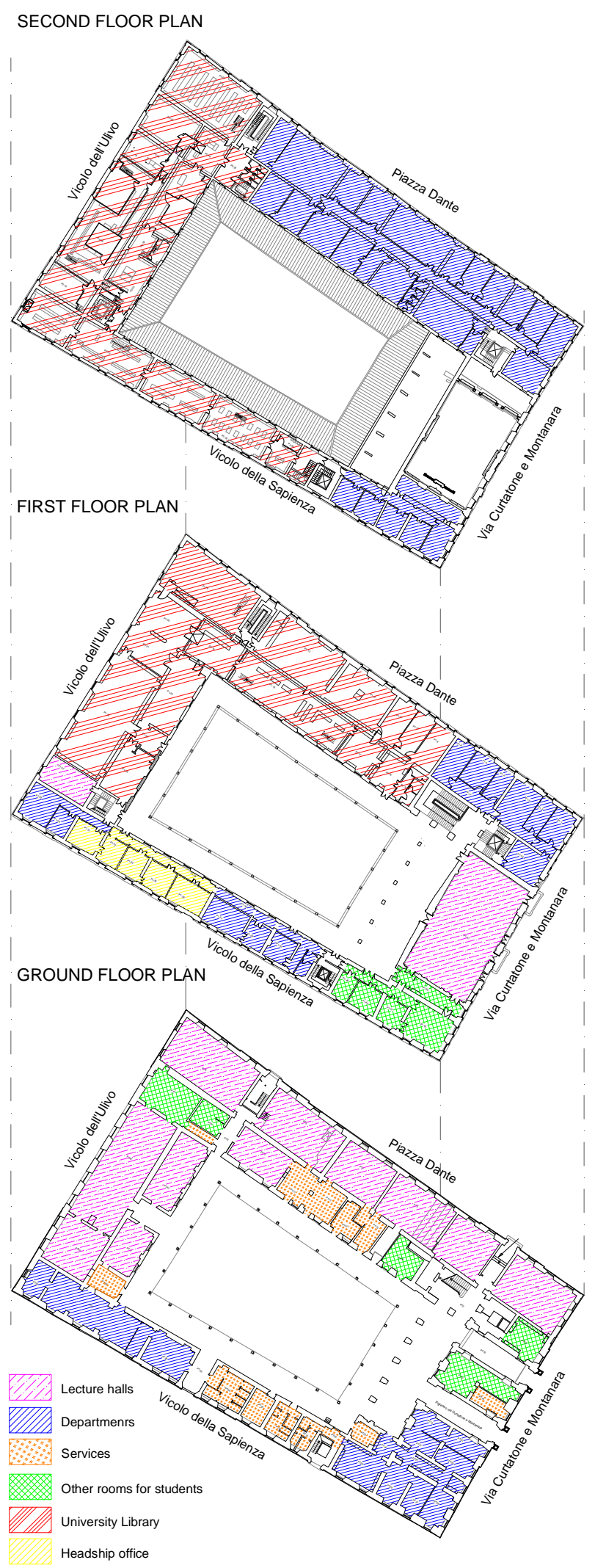

Figure 1: Plan overview of the different levels of the building and use destinations for the different rooms. 
The masonry typologies of vertical walls were determined by removing the plaster on $50 \times 50 \mathrm{~cm}$ portions with following endoscopic examination to check the presence of cavities or adjacent facings of different thickness and type. Figure 2 shows the periods of realization of vertical walls of the ground floor and the corresponding variability of revealed masonry typologies: six different patterns and the absence of suitable connections between perpendicular walls were determined.

Different types of horizontal structures are present in the building: the ground floor (Figure 3 ) shows cross or cloister vaults with solid-brick masonry, mainly located in correspondence of the ancient and not modified areas of the Palace - such as in the rooms around the internal courtyard parallel to Piazza Dante and Via dell'Ulivo. The double-height Aula Magna is topped by a masonry/r.c. vault. Floor slabs made of steel and brick blocks in single or double bonds - mainly located in correspondence of Piazza Dante at the ground floor and, in general, at $1^{\text {st }}$ and $2^{\text {nd }}$ floor, portions of the building that suffered for progressive modifications, enlargements and transformation due to use requirements - were also deeply surveyed to obtain information regarding structural profiles and weight of the upper filling layers.

The roofing structure, consisting of trusses of different types and materials is the result of the modifications undergone by the building over the years. On the Piazza Dante side, steel Polonceau trusses (similar to those over the double-height of the new Aula Magna, dated back to the early $20^{\text {th }}$ century) are located; the other sides of the building present wooden trusses of different sizes and shapes, with various degrees of deterioration due to the poor maintenance, bad connections among elements, presence of small solid-brick walls to support the bearing elements, accumulations of debris etc., resulting from operations aiming at compensating for local deficiencies but losing sight of the building and its overall structure.

The cracking scenario present in several portions of the building (with different concentration and entity) is the result of the modifications undergone by the Palace during the centuries, with increasing acting load due to the library, to the activities developed inside the building and to the differential subsidence related to the heterogeneity of soil and foundation structure (Figure 3). The progressive growth of the cracks, especially in proximity of the separations of the structural units, is still quite evident in the building's vertical and horizontal surfaces: as an example, a wide cracking scenario was revealed in the corner between Via Curtatone e Montanara and Via della Sapienza, born by the incorporation of ancient tower houses into the current structure, and in correspondence of the vaulted surfaces of colonnade and internal arcade, characterized by the presence of different foundation settlements and by structural problems yet identified during the $18^{\text {th }}$ and $19^{\text {th }}$ centuries (Figure 3). Two monitoring systems (one periodic with fixed steel reference gauges and one continuous with electronic transducers) were set up in order to determine the possible evolution of the ongoing subsidence and damages (Figure 3). Analysis of the monitoring results enabled the identification of differential displacements, highlighting problems and evolution of structural cracking mainly in correspondence of the vaults of the ground floor colonnade and $1^{\text {st }}$ floor arcade.

The inhomogeneous and inadequacy of the foundation structure to sustain the increasing loads due to the enlargements of the building in relation to the hosted activities was evident by the early 1900s. A deep in situ investigation of foundations was executed through microcore samplings at different angles in the proximity of the masonry walls, at locations planned according to the evolutionary reconstruction of the building: different types of foundations (for both size and depth) were determined (Figure 3). The investigations performed in correspondence to the interior colonnade revealed the absence of connections between single columns, with an isolated square footing placed at $-1.90 \mathrm{~m}$ from ground level, below the foundation of the portico pillars, laid at $-1.75 \mathrm{~m}$. 


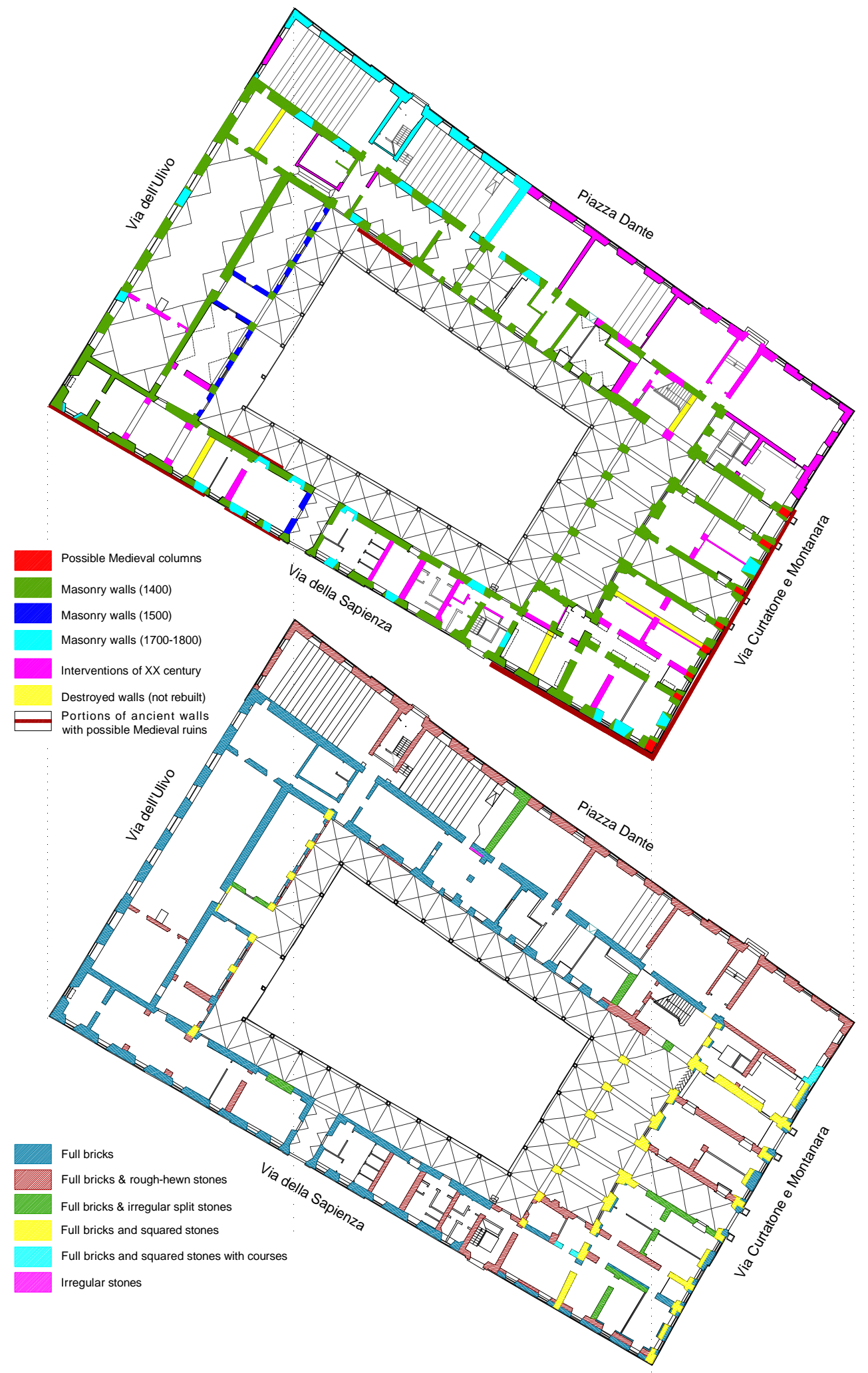

Figure 2: Hypothesis of the evolutive development of the building and plan of ground floor with indications of the various types of masonry. 


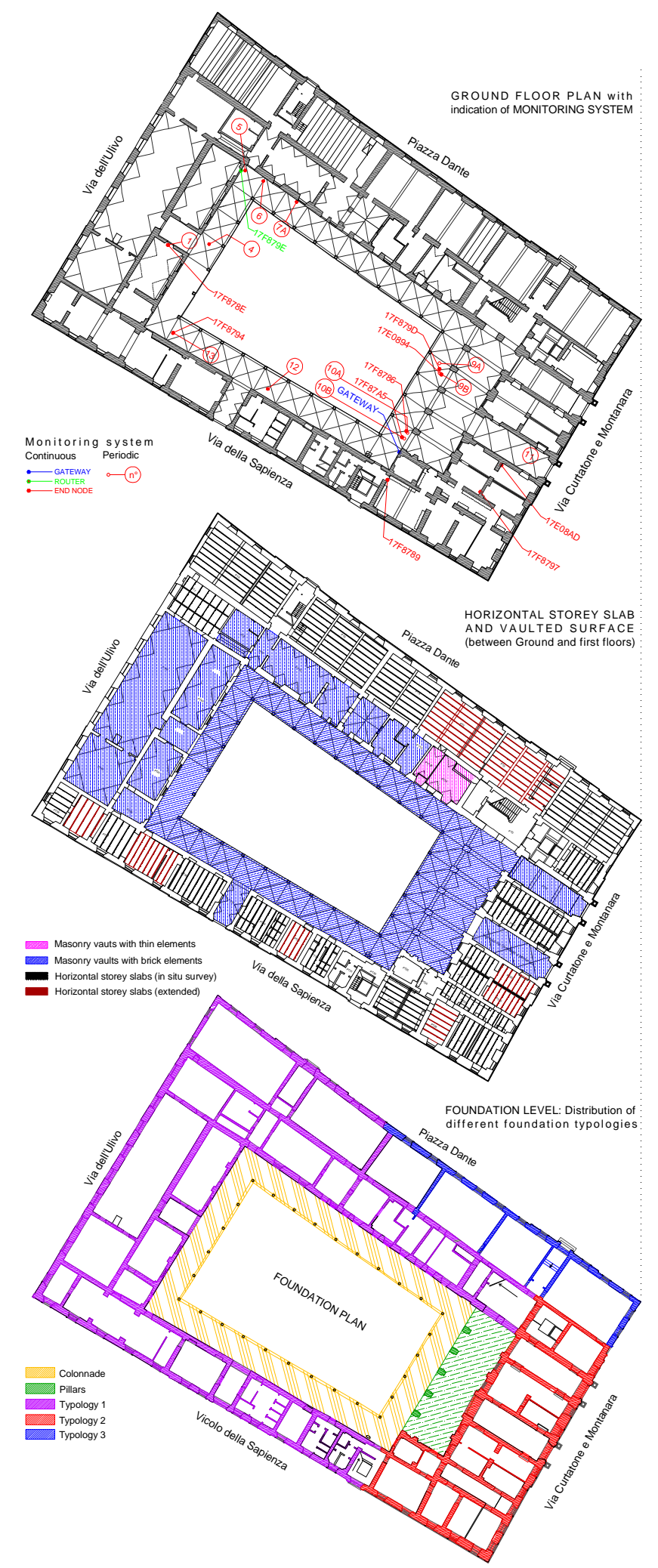

Figure 3: Distribution of the floor slabs and types on the building's ground floor, Foundation plan, different typologies evidenced and ground floor plan with indication of monitoring points.

The foundation of the portico interior walls reaches different depths (between $-1.0 \mathrm{~m}$ and $1.5 \mathrm{~m}$ ), with width varying between 1.50 and $2.40 \mathrm{~m}$. The two investigations performed along Vicolo dell'Ulivo provided similar results, with foundation depths of 2.75 and $2.10 \mathrm{~m}$, and 
widths of 1.75 and $1.60 \mathrm{~m}$, respectively. The Piazza Dante side foundation reaches a depth of about $-1.50 \mathrm{~m}$ below with a width of $0.90 \mathrm{~m}$.

Deep investigations were executed to determine the geotechnical parameters and properties characterizing the foundation soil. Several experimental tests, including continuous core drillings, static penetration tests, tests with seismic dilatometer and dynamic penetration tests were executed. The obtained information allowed determining the local seismic response spectrum: a preliminary one-dimensional analysis under free-field conditions was performed. The procedure used for the local response seismic analysis is deeply presented in [15].

\section{DISAGGREGATION AND ANALYSIS OF STRUCTURAL UNITS}

\subsection{Recognition of structural units}

Critical issues of the structural aggregate were identified with reference to the single structural units recognized as constitutive parts of the building. The Palace was considered as composed by a suitable number of units connected by horizontal structures (foundations, floors and vaults, roof) influencing the mutual interactions among portions, preventing or activating local mechanisms. Structural units were identified in relation to the morphological/structural evolution of the Palace [17], to the modifications undergone during the centuries, to the presence/absence of connections among vertical and horizontal elements and to the interpretation of the cracking scenario. The behaviour of such units was investigated firstly separately and then the framework of the aggregate itself.

A diffused lack of connection between masonry walls was evidenced (Figure 4a) and different masonry typologies were revealed even in the same element: Figure $4 \mathrm{~b}$ and Figure $4 \mathrm{c}$, for example, show the presence of masonry arches of ancient openings nowadays closed due to the modified functional needs. The heterogeneity of masonry walls is higher at the ground and first floors (i.e. corner Via Curtatone e Montanara / Via della Sapienza, Figure 2) respect to the second level, realized at the beginning of the $19^{\text {th }}$ century.

Horizontal floors and roofing systems can allow the connection among masonry walls, preventing the activation of local mechanisms; the horizontal systems of Palazzo La Sapienza are characterized by the presence of vaulted surfaces (mainly at the ground floor where no significant changes took place) and more recent floors with steel profiles (Figure 3 ). If vaulted structures can constitute a rather significant restraint for vertical structural elements, horizontal steel slabs cannot be considered a "rigid" diaphragm. A considerable geometric heterogeneity of foundations, influencing the mechanical response of the building and its bearing capacity in relation to the variable stiffness of the soil, was also evidenced.

Such more or less rigid systems connect several different structural units resulting from modifications executed during the centuries; according to the results of structural/architectural/geotechnical surveys, the following systems can be identified as "independent structural units inside the aggregate", as simply summarized in Figure 5:

1. Corner between Via Curtatone e Montanara and Via della Sapienza.

2. Open gallery and arcade at the ground floor and colonnade at the first floor.

3. Aula Magna and adjacent rooms at ground floor.

4. Double volume of the Aula Magna Nuova at the first/second floor.

5. Portion of the building facing Piazza Dante.

6. Portion parallel to Piazza Dante facing the internal courtyard (ground and first floors).

7. Second floor of the Palace. 
1. Corner between Via Curtatone e Montanara and Via della Sapienza. As visible from Figure 2, pillars characterized by the presence of full bricks and squared stones demonstrate the pre-existence of ancient tower houses incorporated and connected to adjacent masonry structures during the centuries. The discontinuity and heterogeneity of masonry belonging to different constructive typologies, realized in different periods and not connected to one another yielded, during the years, to the development and to the progressive spreading of a diffused cracking scenario visible both in vertical elements and in horizontal structures, allowing the clear identification of this structural unit.

2. Open gallery and arcade at the ground floor and colonnade at the first floor. The internal arcade and the open gallery facing the entrance along Via Curtatone e Montanara at ground floor are characterized by the presence of vaulted cross surfaces with different geometries and heights. The damages present in correspondence of the extrados of the vaults are the result of relative differential subsidence of foundations characterized by different width and depth (Figure 3), already demonstrated by past damages [17]. The absence of horizontal connection between the pillars of the internal arcade make the columns behave "separately" from one another, with relative displacements and rotations. Relative displacements between the wooden roof of the colonnade and the masonry walls are also clearly visible.

3. Aula Magna and adjacent rooms at ground floor. The portion of the building at the ground floor facing Via dell'Ulivo houses the historical Aula Magna and additional rooms once used for teaching activities. The Aula Magna and the adjacent room, actually characterized by the presence of a partition wall, present the same vaulted surface on which the masonry wall at the first floor directly loads [17]. The two teaching rooms facing the courtyard are the result of the closure of the original lodge that, on the western part of the Palace, exactly reproduced the opposite situation of the arcade, as justified by ancient plans and through the analysis of the cracking scenario and from the observation of the masonry pillars of the original colonnade (Figure 2).

4. Double volume of the Aula Magna Nuova at the first/second floor. The double volume of the Aula Magna Nuova, generated at the end of the $19^{\text {th }}$ century in relation to the modifications of the building necessary to overcome the new use requirements, has an internal open space not provided by transversal retaining walls (demolished in 1905) and characterized by the lack of horizontal restraints between the two opposite facades. The roofing system presents brick truss with r.c. elements and masonry lightening blocks (thickness $3.0 \mathrm{~cm}$ ) not able to constitute a rigid diaphragm.

5. Portion of the building facing Piazza Dante. The block constituted by the rooms facing Piazza Dante can be considered a separate structural unit, generated in a more recent period [17], modified at the beginning of the $20^{\text {th }}$ century and clearly distinguishable from the rest of the building due to the presence of horizontal steel storey slabs and of masonry walls not connected to the pre-existences. This situation is clearly visible both at the ground and the first floor.

6. Portion parallel to Piazza Dante facing the internal courtyard. The architectural and structural surveys of the building evidenced the absence of perpendicular walls in correspondence of the first floor of the building in the portion facing the internal courtyard and parallel to Piazza Dante: the increasing need of place for the library and the new activities developed in the building leaded to the demolition of the walls perpendicular to the internal main façade, generating the activation of overturning mechanisms due to the absence of transversal restraints. 
7. Second floor of the Palace. The $2^{\text {nd }}$ floor of the building, according to the morphological and structural analyses of the Palace, can be considered a "separate" structural unit [17], characterized by a more recent edification and a more homogeneity for what concerns materials, masonry organization and floor typologies.
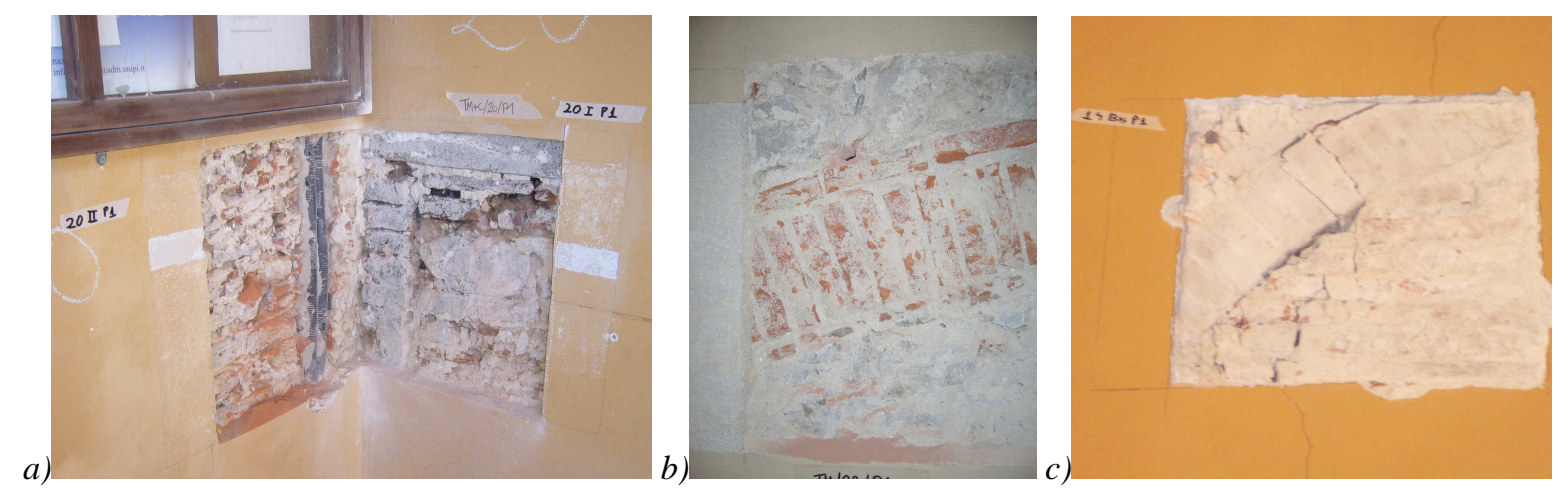

Figure 4: Discontinuities of vertical masonry walls: a) absence of connection between perpendicular walls, b-c) arches identified in correspondence of the first floor level, probably old windows currently closed.

\subsection{Analysis of structural units of the building}

The structural behaviour of the significant portions of the building (Figure 5) was analyzed through the adoption of local models able to reproduce their main features on the base of the knowledge obtained from in situ and experimental investigations. With reference to the list already elaborated for structural units, the following Limit States (LS) and vulnerabilities (V) can be determined.

\section{Corner between Via Curtatone e Montanara and Via della Sapienza}

A diffused cracking scenario is visible in correspondence of this area, directly related to the differential subsidence of foundations, with relative displacements that strongly affects the overall structural aggregate, and to the intrinsic nature of the masonry of vertical walls. The widespread discontinuities in the structure's geometry, materials and constraints, the presence of voids, air spaces and facings, together with the dubious degree of collaboration, lead to local stress concentrations confirmed by the results of the experimental flat jack tests and by the extensive cracking phenomena.

\section{Open gallery and internal arcade at the ground floor and colonnade at the 1st floor}

The relative displacements evidenced in correspondence of the wooden elements of the colonnade at the $1^{\text {st }}$ floor and the masonry walls, as well as the diffused cracking scenario revealed in the crossed vaulted surfaces of the ground floor are the direct consequence of the differential subsidence due to the different typologies of foundations (Figure 3). The foundations of columns of the internal arcade are not connected to one another and lay at different levels respect to the masonry walls facing the courtyard: these differences result in relative subsidence evidencing the non uniformity of the overall mechanical response of the foundation system, the variability of soil stiffness and of ultimate loads. The structural analysis of foundations considering actual loads (permanent, live and seismic action) allowed the determination of the unit load-subsidence diagrams of the foundation-ground assemblage of the various analyzed sections (Figure 6a): the difference between the building's perimeter and its interior (i.e. colonnade and pillars of the interior courtyard) can expose the whole structure to considerable damages in those areas where significant differences in stiffness and loads were measured (Figure 6b). 


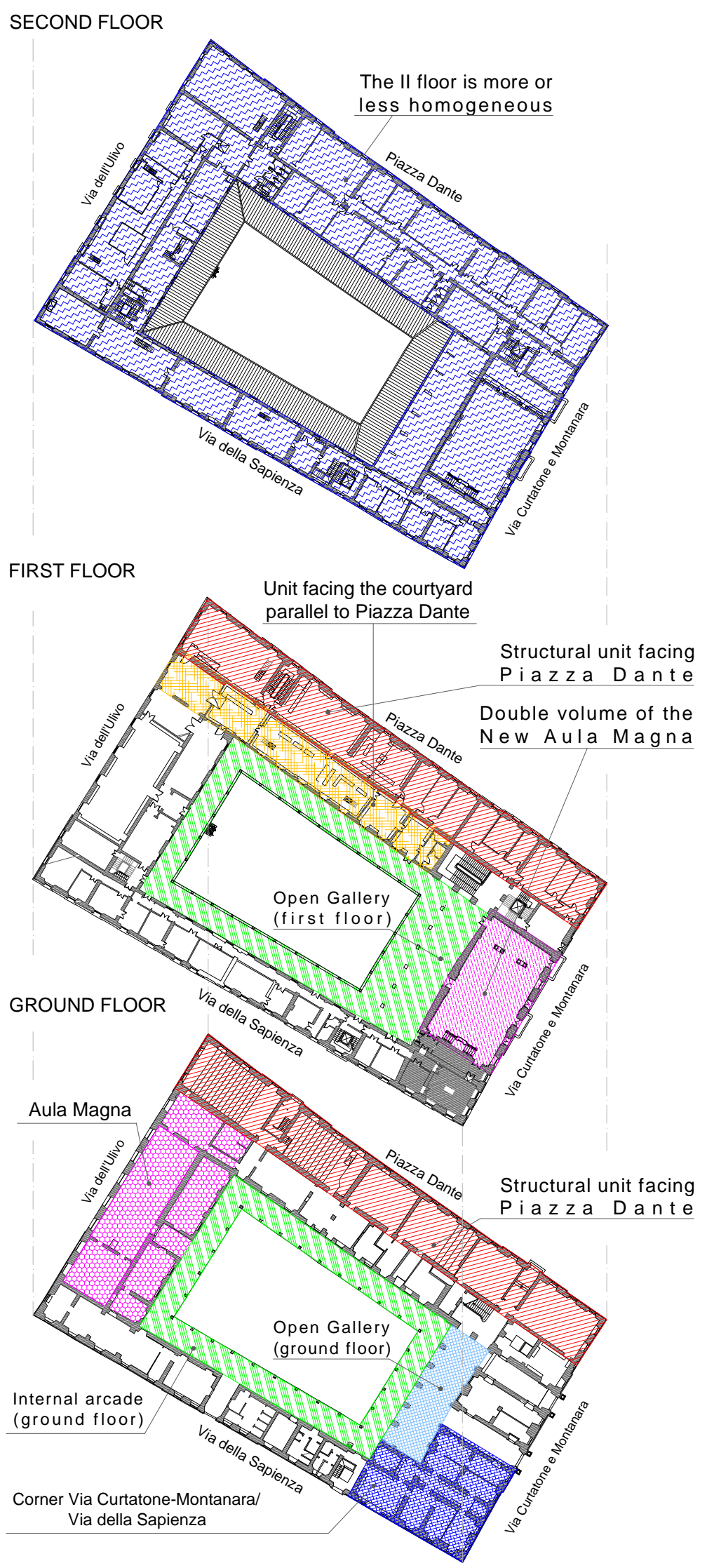

Figure 5: Structural units that can be determined as independent parts of the aggregate. 


\section{Aula Magna and adjacent rooms}

The progressive enlargement of the building at the 1st floor necessary to house the library lead to the introduction of a solid brick curtain wall in order to separate the library rooms and those used for teaching activities. The masonry wall - with thickness equal to $17 \mathrm{~cm}$, height equal to two floors - according to Figure 4 was already present at the end of the $16^{\text {th }}$ century and nowadays represents the effective separation between the portion of the building belonging to the University of Pisa and the University Library. The wall directly rests upon the vaulted surface of the room adjacent to the Aula Magna, generating a critical situation especially in presence of seismic action. Moreover, the analysis of the cracking scenario affecting the Aula Magna at the ground floor, the adjacent rooms and the other areas facing the internal courtyard (Figure 5) is strictly related to the progressive modifications executed during the centuries. Severe damages can be observed in correspondence of the vertical masonry walls and in the vaulted surfaces of the two rooms facing the internal court: at the origin of the Palace, this portion was directly part of the colonnade (Figure 2) and the closure of the area was dated around the end of the XVI century; the relative displacements between the colonnade and the vertical masonry walls of the building - as well as proved by the analysis of the monitoring data - are directly connected to the evidenced cracking scenario.

\section{Aula Magna Nuova: double volume at first and second floor}

The analysis of the double volume $\left(1^{\text {st }}\right.$ and $2^{\text {nd }}$ floor) of the New Aula Magna evidenced cracks in the vertical masonry walls (not perfectly visible due to presence of ancient paintings) and on the vaulted surface. A deep in situ investigation allowed the determination of the effective structure of the roofing system: steel Polonceau trusses - dating back to the early 20th century - are present sustaining the roof, while the vaulted surface is made up of thin brick elements $(3.0 \mathrm{~cm})$ positioned between main r.c./masonry truss with a typical shape used not to transfer horizontal thrusts to the masonry walls. Cracks visible in correspondence of the vaulted surface are, mostly, due to the "geometrical" distance of light brick elements; the support of those elements in correspondence of the main bearing truss is equal, at maximum, to $3.0 \mathrm{~cm}$, generating the possible detachment with the following risk to people and to the structure itself. The overturning phenomena of external and internal walls was analyzed following the linear kinematic approach: the PGA activating the mechanism was equal to $0.112 \mathrm{~g}$ respect the design value of $0.118 \mathrm{~g}$.

\section{Portion parallel to Piazza Dante facing the internal courtyard}

The progressive increase of space due to the need to house the libraries during the last centuries - executed through the demolishing of internal walls and the introduction of mezzanines at the $1^{\text {st }}$ and $2^{\text {nd }}$ floors - leaded to overload the bearing structures, significantly altering their original local response towards dynamic loads and exposing the building to outof-plane instability in correspondence of the walls to which the mezzanines' cantilever beams are anchored, characterized by the lack of adequate restraints between perpendicular walls. The out-of-plane problems were evident in correspondence of the sub-unit facing the internal courtyard and parallel to Piazza Dante $\left(1^{\text {st }}\right.$ and $2^{\text {nd }}$ floors), resulting from progressive modifications and demolitions of masonry walls as widely evidenced by the historical analysis). Since typical mechanisms were recognized (i.e., the overturning of masonry vertical walls), linear kinematic analysis was adopted for the determination of the value of horizontal peak ground acceleration (PGA) activating the mechanism. The internal masonry wall is not provided by perpendicular retains, resulting in the possibility to activate the global overturning of the wall both at first and second level: the PGA leading to the activation of the 
collapse overturning mechanism were respectively equal to $0.060 \mathrm{~g}$ and $0.079 \mathrm{~g}$ for the $1^{\text {st }}$ and the $2^{\text {nd }}$ floor, towards a foreseen design PGA equal, for the considered site, to $0.118 \mathrm{~g}$.
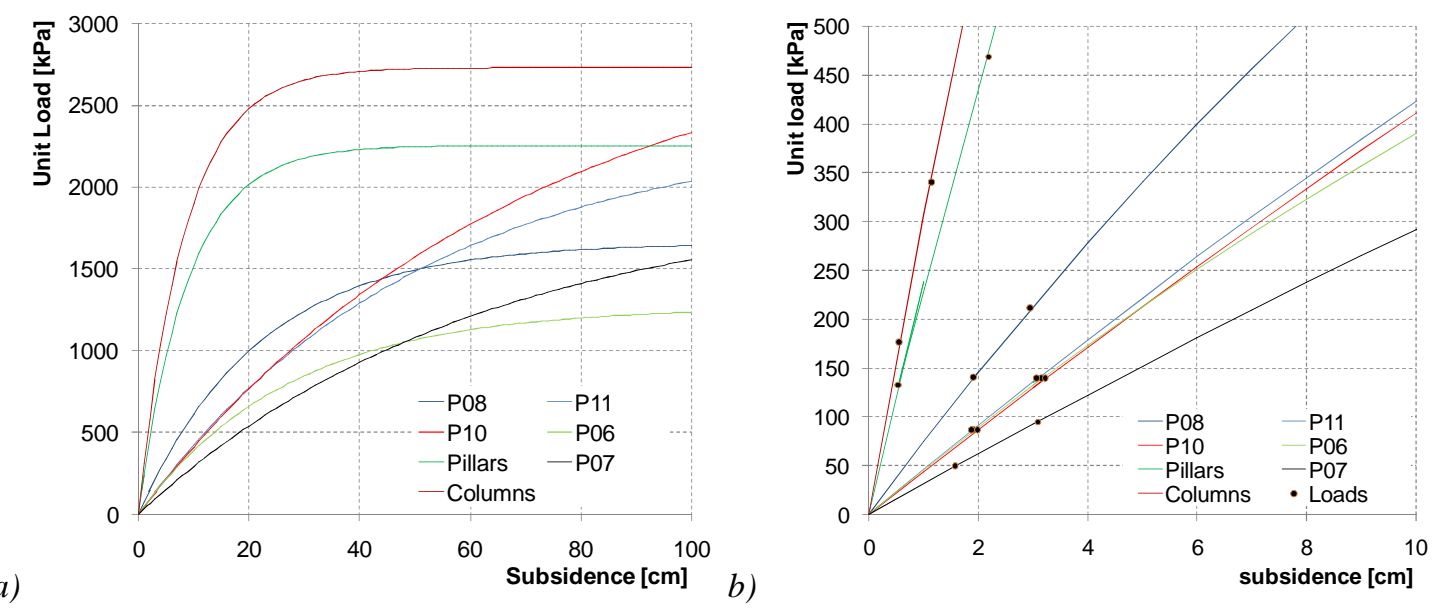

Figure 6: a) Unit load-subsidence curves for the different sections investigated, b) estimates of the subsidence of different building zones as a function of the applied loads.

\subsection{Structural behaviour of the aggregate}

Even if not strictly necessary for the understanding of the behaviour of a structural aggregate, in Italy the elaboration of a global three-dimensional model is nowadays required [3]) for the execution of safety checks on masonry vertical walls (i.e. shear, flexure in and out of the plane); the global model represents an improved condition respect to the effective situation of the Palace.

A simplified FEM model of the building was realized using SAP 2000, with twodimensional elements for masonry walls and vaulted surfaces modelled as equivalent plane elements and one-dimensional elements for the steel profiles of the floor slabs, the roofing and the university library mezzanines. The soil-structure interaction was represented through the Winkler model, with elastic three-directional springs calibrated according to the results of the geotechnical investigations and in relation of foundations' shape and size. Cracking phenomena of masonry were considered by reducing the stiffness to values equal to $80 \%$ and $60 \%$ of the undamaged conditions respectively on the ground and the first and second floors [18]. Linear dynamic analysis with response spectrum was performed; a behaviour factor equal to 2.25 was adopted, conservative in comparison to the values contained in the 2010 Guidelines [13]. Global vibration modes were determined for both flexural behaviour in $\mathrm{x}$ and $\mathrm{y}$ directions; the significant periods ranged between $0.89 \mathrm{~s}$ (global flexural mode in y direction) and $0.59 \mathrm{~s}$.

The described model it is not clearly able to include the extreme variability and strong nonlinear behaviour of constituent materials as well as complex behaviour of internal and external restraints among single structural elements and structural units, anyway can provide useful information when a critical analysis of results is executed basing on the multidisciplinary studies conducted on the building and on the results obtained on single structural units.

The safety checks were performed in agreement with D.M.14/01/2008 [3]. The most evident criticisms were revealed in correspondence of the portions of the building characterized by high heterogeneity of materials and structural typologies and in those areas that underwent the most significant changes and modifications during the centuries, confirming the considerations coming from the analysis of the structural behaviour of single 
portions or units determined inside the aggregate (Figure 5), such as in correspondence of the corner Via Curtatone e Montanara/Via della Sapienza (i.e. heterogeneity of materials), of the historical Aula Magna (i.e. closure of the colonnade), of the New Aula Magna (i.e. modifications and enlargements up to the double volume).

\section{RETROFIT OF THE STRUCTURAL AGGREGATE}

The traditional global approach proposed by current standards for retrofit, foreseeing the possibilities of global/partial and local strengthening of the whole building or of several structural elements cannot be easily applied to historical buildings. The retrofit of cultural heritage shall pursue the preservation of the original nature of the building, maintaining its historical aspects and providing a considerable increase of the margin of structural safety. The retrofit can be considered, then, the final amount of many local interventions: local retrofit operations regarding single structural units globally cooperate to provide the aggregate with a higher level of structural safety. Many structural interventions were then planned for Palazzo La Sapienza to solve the problems evidenced through the structural analysis, related to the different structural units constituting the Palace. Some of them are briefly summarized in the following pages.

\section{Open gallery at ground floor and colonnade at the first floor}

The retrofit of the vaulted surfaces consisted in the removal of the filling material on the extrados of the vaulted surfaces - with the following decrease of the dead load - and in the restoration of cracks using specific materials for historical masonry buildings (Figure 7a); a similar retrofit procedure was also adopted for cracks present at the intrados of the vaults. A thin shaving layer of 2-3 cm of thickness with welded steel mesh $(\phi 3 \mathrm{~mm}$ and spacing 50x50 $\mathrm{mm}$ ) was also foreseen provide a global behaviour without altering the structural feature of the aggregate. Some problems were revealed also in correspondence of the $1^{\text {st }}$ floor colonnade, with relative displacement between the wooden secondary elements of the roof and the masonry wall, with support length equal, in some cases, only to few centimeters; in order to prevent the pull out of such elements, an additional steel profile was positioned in correspondence of the whole perimeter of the colonnade (Figure $7 \mathrm{~b}$ ), providing a final support length of about $10 \mathrm{~cm}$. Several additional retrofit interventions were designed for damaged elements of the roofing system.

\section{Aula Magna and adjacent rooms}

To solve the problem of the masonry infill wall directly bearing on the vaulted surface close to the Aula Magna at the ground floor, the introduction of a steel HEA profile able to directly sustain the masonry wall and the rest of the superstructure - including the vault at $1^{\text {st }}$ floor and the corresponding masonry wall at the $2^{\text {nd }}$ floor - was accurately designed. The design of the bearing profile took into account both strength and stiffness aspects - this last to avoid the vertical deflection of the masonry wall - and, moreover, the analysis of the assembly procedure (Figure 8). A temporary bearing structure made up of two twin truss beams with transversal support steel beams with spacing equal to $50-70 \mathrm{~cm}$ was adopted, allowing safety conditions during the phases of cutting of the masonry wall and introduction of the HEA bearing beam.

\section{Vertical masonry walls}

Diffused interventions were executed on vertical masonry walls in order to solve the problems related to the diffused cracking scenario revealed and, in some cases, monitored at the different floors of the Palace, such as for example in correspondence of the corner 
between Via Curtatone e Montanara, in which cracks appear mostly in relation to the progressive modifications and changes executed during the centuries as a consequence of functional requirements. Different typologies of interventions were foreseen in relation to the entity of revealed cracks.
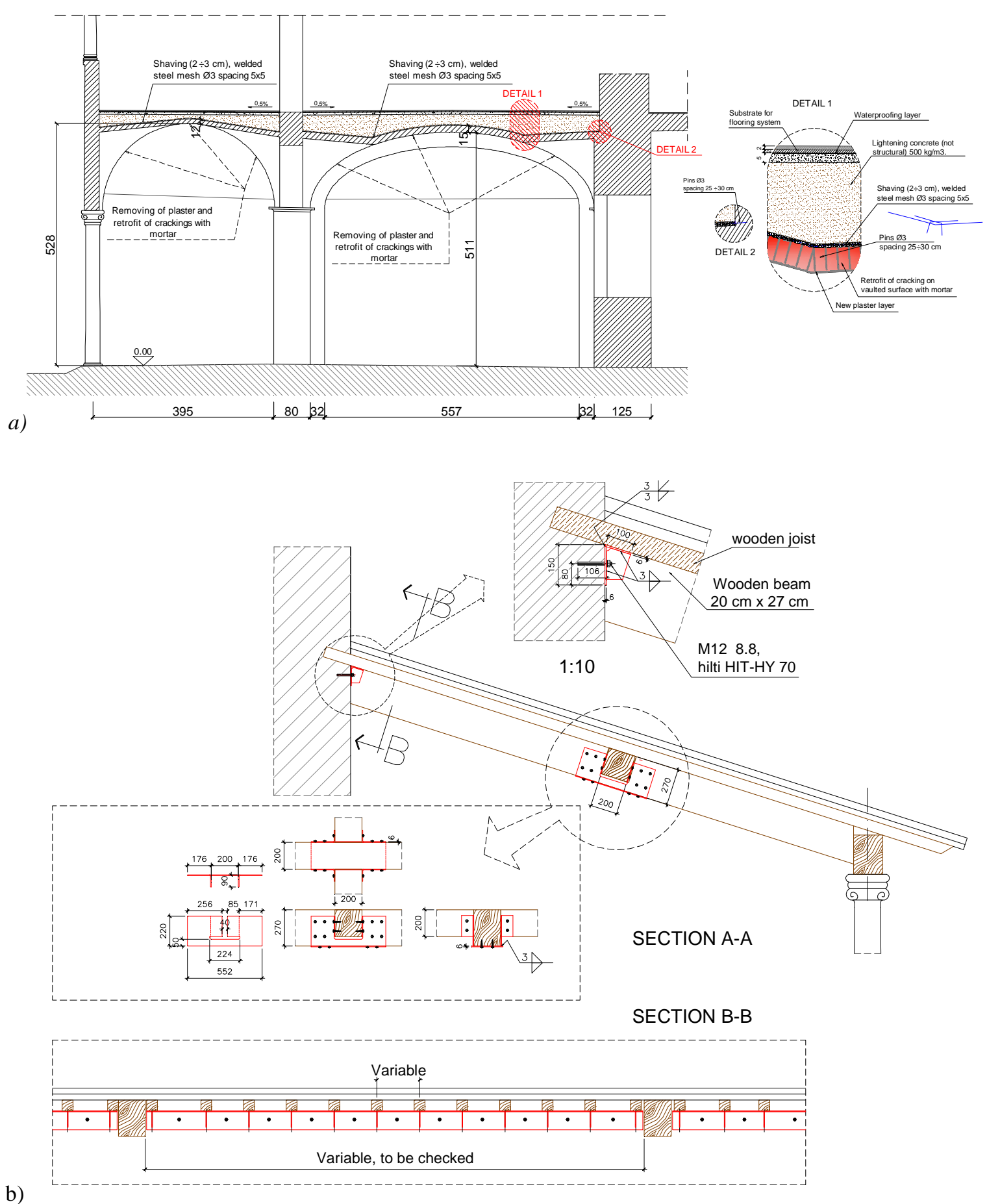

Figure 7: a) Example of the intervention foreseen for the retrofit of the vaulted surfaces of the ground floor arcade; b) retrofit intervention foreseen to provide adequate support to the wooden elements of the first floor colonnade. 

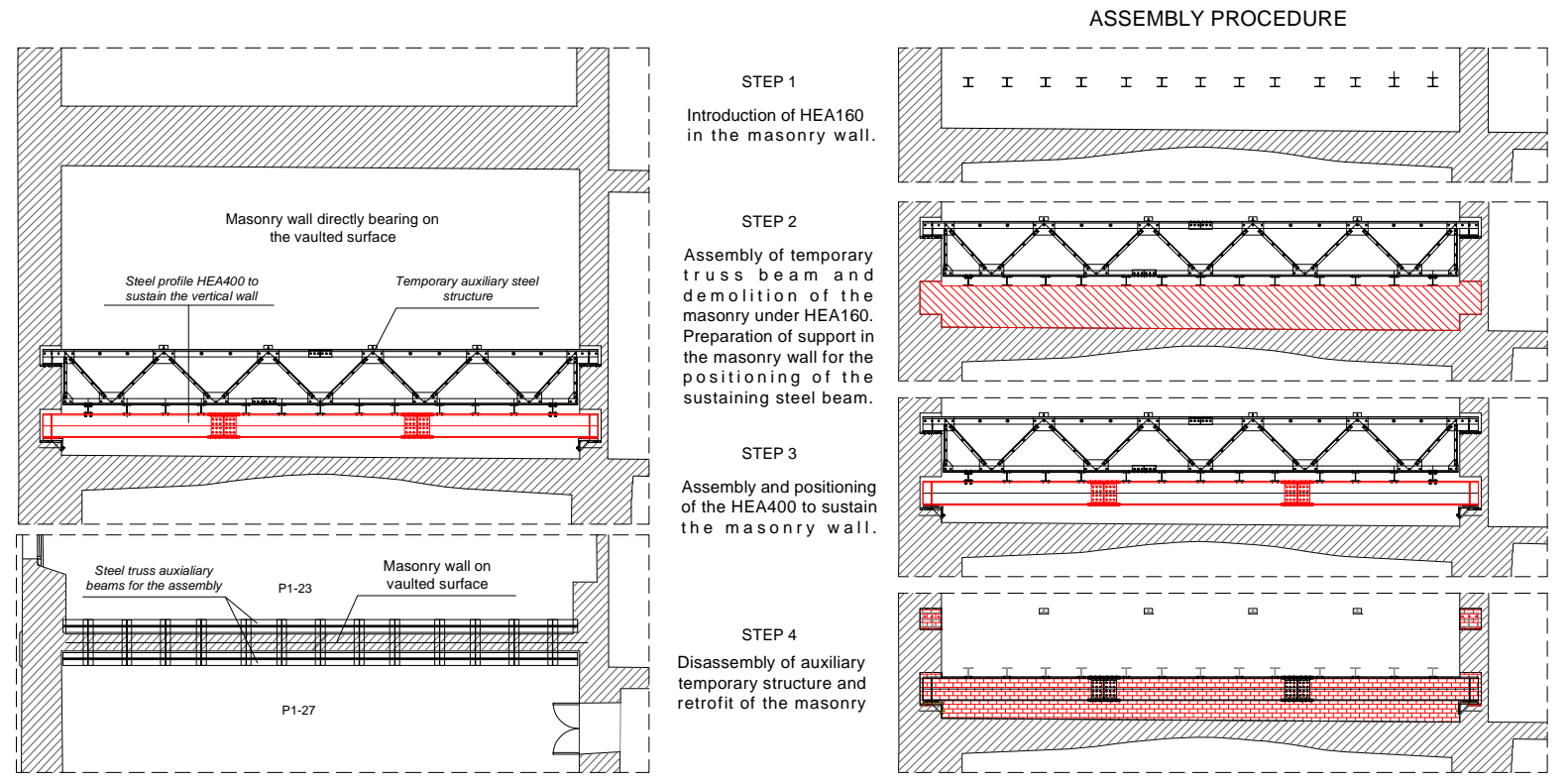

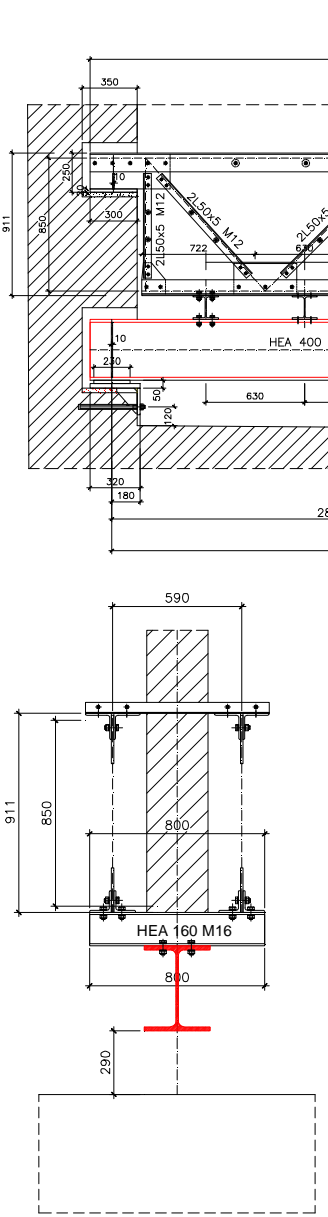

SEZIONE B-B

Struttura reticolare di montaggio

Traversine di sostegno

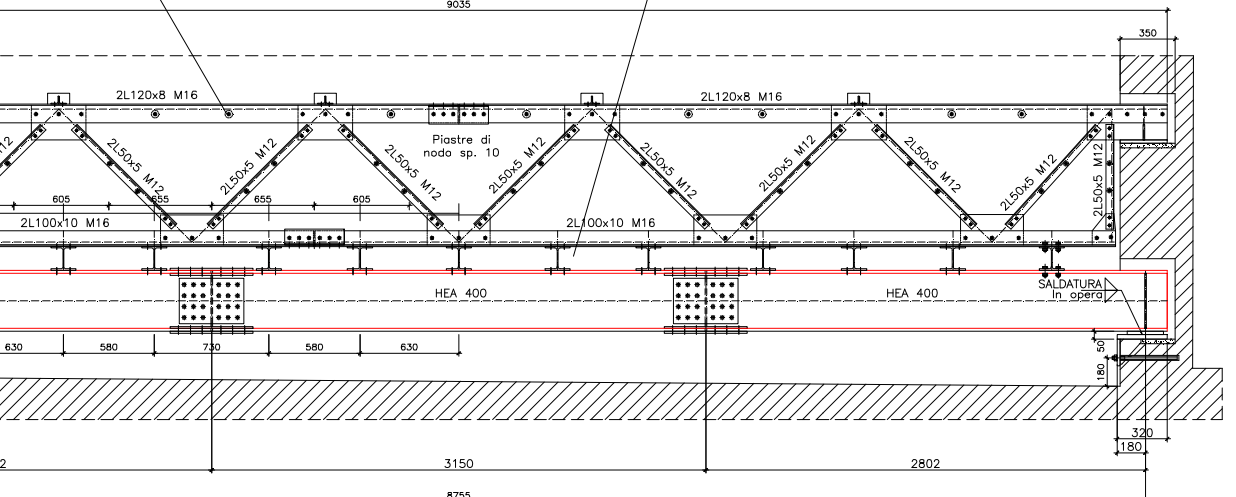

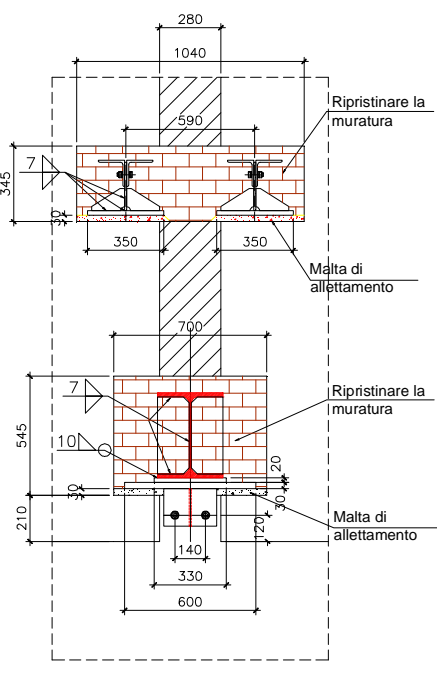

SEZIONE A-A
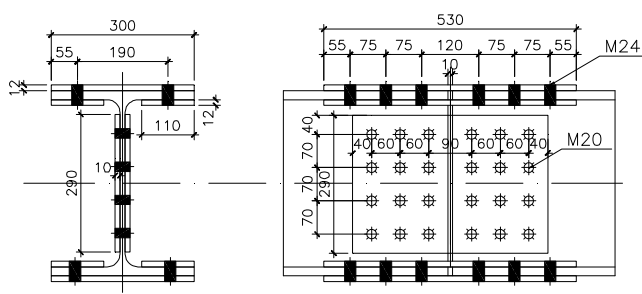

Particolare Coprigiunto

Particolare Appoggio
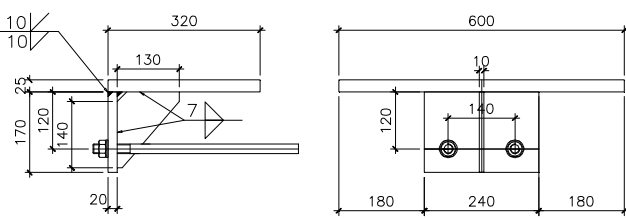

Figure 8: Introduction of stele profile and assembly procedure to avoid the load directly upon the vaulted surface near the Aula Magna. 


\section{CONCLUSIONS}

The deep analysis of the current condition of such complex building as Palazzo La Sapienza in Pisa, including the historical and morphological investigation of its modifications and extensions during the centuries, the in situ survey of materials, walls, horizontal storeys and vaulted surfaces, the analysis cracking scenario, of foundations and roofing system, the geological and geotechnical characterization of the soil highlighted the need to consider the building not as a single structural unit, but rather as an aggregate made up of several units connected to each other and built using different techniques.

The combined analysis of the historical evolution of the Palace and of the structural survey of its current condition - especially for what concerns the cracking scenario and its main causes - allowed the determination of structural units, whose behaviour shall be deeply analyzed on the base of the progressive modifications of bearing elements, acting loads, connections and mutual influence. If, according to current standards for existing constructions a global analysis of the building is necessary for the execution of safety checks, in the present work the need of a "double" analysis including the interpretation of the structural behaviour of sub-units, their mutual interrelationships and the possible activation of significant partial/local mechanisms, and a simplified global analysis providing indications regarding static condition and relative information about the most critical and stressed portion of the building itself, is highlighted.

A critical evaluation of the building's safety, together with a clear, deep understanding and knowledge of the structure itself, constitute the basis to define the objective of any structural interventions, carefully designed to achieve appropriate safety levels, durability of relevant portions of the building and, at the same time, produce the least impact possible on this important living example of Italy's historical heritage.

\section{REFERENCES}

[1] S. Lagomarsino. On the vulnerability assessment of monumental buildings. Bulletin of Earthquake Engineering, 4, 445-463, 2006.

[2] A. Bernardini, S. Lagomarsino. The seismic vulnerability of architectural heritage. In Proceedings of the Institution of Civil Engineers - Structures \& Buildings, 161 (SB4): 171-181, 2008.

[3] D. M. Infrastrutture Trasporti 14 gennaio 2008, Norme Tecniche per le Costruzioni.

[4] CEN (2005). European standard EN1998-3. Eurocode 8: design provisions for earthquake resistance of structures - Part 3: assessment and retrofitting of buildings. European Committee for Standardisation, Brussels.

[5] FEMA 547. Techniques for the Seismic Rehabilitation of Existing Buildings. Federal Emergency Management Agency, Washington DC, 2006.

[6] G. Barbieri, L. Biolzi, M. Bocciarelli, L. Fregonese, A. Frigeri, Assessing the seismic vulnerability of a historical building. Engineering Structures, 57, 523-535, 2013.

[7] G. Chellini, L. Nardini, B. Pucci, W. Salvatore, R. Tognaccini, Evaluation of seismic vulnerability of Santa Maria del Mar in Barcelona by an integrated approach based on terrestrial laser scanner and finite element modelling. International Journal of Architectural Heritage, 8(6), 795-819, 2014. 
[8] V. Mallardo, R. Malvezzi, E. Milani, G. Milani, Seismic vulnerability of historical masonry buildings: a case study in Ferrara. Engineering Structures, 30, 2223-2241, 2008.

[9] S. Lagomarsino, S. Cattari, PERPETUATE guidelines for seismic performance-based assessment of cultural heritage masonry structures. Bulletin of Earthquake Engineering, 13, 13-47, 2015.

[10] D. D'Ayala, S. Lagomarsino, Performance-based assessment of cultural heritage assets: outcomes of the European FP7 PERPETUATE project. Bulletin of Earthquake Engineering, 13, 5-12, 2015.

[11] M. Kržan, S. Gostîc, S. Cattari, V. Bosiljkov, Acquiring reference parameters of masonry for the structural performance analysis of historical buildings. Bulletin of Earthquake Engineering, 13, 206-236, 2015.

[12] C.S. Oliveira, Seismic Vulnerability of Historical Constructions: A Contribution. Bulletin of Earthquake Engineering, 1: 37-82, 2003.

[13] Linee Guida per la valutazione e riduzione del rischio sismico del patrimonio culturale allineate alle nuove Norme Tecniche per le Costruzioni (D.M. 14/01/2008), 2010.

[14] S. Caprili, F. Mangini, W. Salvatore. Numerical modelling, analysis and retrofit of the historical masonry building La Sapienza. COMPDYN 2015, $5^{\text {th }}$ ECCOMAS Thematic Conference on Computational Methods in Structural Dynamics and Earthquake Engineering, Crete Island, Greece, 25-27 May, 2015.

[15] S. Caprili, F. Mangini, W. Salvatore, G. Scarpelli, N. Squeglia. Influence of soilfoundation-structure interaction on overall behaviour and diseases of a medieval building in Pisa. STREMAH 2015, $14^{\text {th }}$ International Conference on Studies, Repairs and Maintenance of Heritage Architecture, La Coruna, Spain, July 13-15, 2015.

[16] S. Caprili, F. Mangini, W. Salvatore, Evaluation of structural safety and seismic vulnerability of historical masonry buildings: studies and applications in Tuscany Region. STREMAH 2015, $14^{\text {th }}$ International Conference on Studies, Repairs and Maintenance of Heritage Architecture, La Coruna, Spain, July 13-15, 2015.

[17] E. Karwacka Codini, Analisi storico-critica dell'edificio della Sapienza, Regesto documentario, in Verifica della sicurezza statica ed analisi della vulnerabilità sismica dell'edificio La Sapienza di Pisa, coordinatori scientifici Walter Salvatore, Università di Pisa, e Paolo Iannelli , Ministero dei Beni e delle Attività Culturali e del Turismo, Pisa 2014, pp. 21-85.

[18] T. Paulay, M.J.N. Priestley, Seismic design of reinforced concrete and masonry buildings. John Wiley and sons, INC. New York, U.S.A, 1991. 